\title{
Atmospheric Pressure Plasma Polymerization of In Situ Doped Polypyrrole
}

\author{
Roel Dams ${ }^{1}$, Dirk Vangeneugden ${ }^{*}, 1$ and Dirk Vanderzande ${ }^{2}$ \\ ${ }^{I}$ VITO, Materials Department, Boeretang 200, 2400 Mol, Belgium \\ ${ }^{2}$ University of Hasselt, Division Chemistry, Agoralaan, Building D, 3590 Diepenbeek, Belgium
}

\begin{abstract}
The conjugated polymer polypyrrole can be useful in a lot of applications such as LEDs, solar cells, organic thin film transistors, (bio)sensors, corrosion protection and antistatic layers. However, today, large area coating is still difficult. For this reason, plasma deposition at atmospheric pressure is presented as an alternative synthesis method, because of its possibility for inline processing and in situ doping. Furthermore, plasma polymerization is a more environmental friendly dry technique. Injection of a pyrrole aerosol into a nitrogen plasma and in situ doping by coinjection of NOBF4 or iodine, results in polymerization and coating deposition. The so formed coatings are analyzed with XPS, FTIR, UV/VIS, and resistance measurements. Conductivities up to $10^{-3} \mathrm{~S} / \mathrm{cm}$ were reached.
\end{abstract}

Keywords: Atmospheric pressure, plasma, pyrrole, conducting polymers.

\section{INTRODUCTION}

In general, organic polymers are known to be electrical insulators. However, since the revolutionary discovery of conductivity in doped polyacetylene in 1977 by the groups of Alan J. Heeger, Alan G. MacDiarmid and Hideki Shirakawa, a new group of polymers i.e. conjugated polymers, was born [1]. Nowadays, conjugated polymers are the subject of numerous investigations towards their applicability in polymeric LEDs [2, 3], organic thin film transistors (OTFTs) [4], photo detectors [5], (bio) sensors [6], hybrid and/or all organic solar cells and photovoltaics [7], corrosion inhibiting coatings [8], and antistatic layers. The main advantages for applying conjugated polymers are the production of large-area applications, film flexibility and reduced production cost.

Chemical and electrochemical synthesis of conjugated polymer coatings is well described in literature $[9,10]$. However, both methods have their drawbacks. In general, the typical structure with alternate single and double bonds leads to rigid, insoluble polymers. Processing of the polymers, resulting from chemical polymerization is therefore difficult. If the substrate is conductive, this problem can be solved by using electropolymerization with deposition directly on the substrate. Nevertheless, both chemical and electrochemical syntheses, are usually performed in batch processes. This is the reason why, until today, they are mostly used for small scale applications with high added values. High speed, inline processing, with low production cost, is not possible for certain applications.

Recently, synthesis of thin polymer films by use of plasma polymerization has emerged as an interesting new approach. Applying an alternating electric field on a gas

*Address correspondence to this author at the VITO, Materials department, Boeretang 200, 2400 Mol, Belgium; Fax: +32 143211 86;

E-mail: Dirk.Vangeneugden@vito.be results in a highly energetic condition by the creation of gas ions, radicals and excited molecules. This energetic state is called plasma. Typical for plasma's is the emission of light originating from the return of the excited molecules to their ground state. When a monomer is injected into the plasma, collisions with the energetic gas molecules and electrons lead to activation of the monomer. Reaction between activated monomers results in coating deposition.

Plasma polymerization is a 'dry' technique that does not require the use of solvents. From an ecological and economical point of view, the absence of solvents and solvent waste offers a lot of advantages. At first, plasma polymerization was used for the formation of thin passive layers but it has recently found its way towards other applications. Some of those applications incorporate the deposition of conjugated polymers. Plasma polymerization of pyrrole at low pressure has already been reported [11-25]. However, since this technique requires a high vacuum, it can only be done in a batch process. For continuous processing, polymerization should be done in a plasma reactor that can work at atmospheric pressure.

In this paper, plasma polymerization of pyrrole at atmospheric pressure is described. Besides the possibility of in-line processing, plasma polymerization at atmospheric pressure has some other advantages over deposition at low pressure. Since the chance that a gas molecule collides with another is higher at atmospheric pressure than in vacuum, energy transfer is more efficient. At vacuum pressure, the monomer molecules are often fragmented, because the plasma species are highly energetic. The lower energy of plasma species at atmospheric pressure results in a better retention of the chemical structure. Furthermore, the higher monomer concentration at atmospheric pressure results in higher deposition speeds.

Simultaneous addition of a dopant in the plasma leads to in situ doped polypyrrole coatings. A detailed characterization 
of these polymers is done with the help of conventional techniques such as FT-IR, UV/VIS and XPS.

\section{EXPERIMENTAL SECTION}

\section{Materials}

The monomer used is pyrrole (98\%, Sigma Aldrich). Iodine (99.8\%, ACS reagent, Sigma Aldrich) was used as a dopant. A second dopant, nitrosonium tetrafluoroborate (98\%, Fluka) was used as a 5\% wt solution in ethanol (PA, $>99.9 \%$, Merck). All reagents were used as received.

\section{Plasma Deposition}

The plasma is generated with a dielectric barrier discharge between two horizontally placed electrodes. The lower electrode is covered by a glass dielectric of $5 \mathrm{~mm}$ thickness, while the upper electrode is uncovered. A high ac voltage is used on the lower electrode. Power is supplied by an AFS generator that is carefully tuned for the used frequency and the specific electrode configuration, in order to minimize power losses. The upper electrode is grounded. The gap between the glass dielectric and the uncovered electrode is $2 \mathrm{~mm}$. All reactions occurred at a fixed frequency of $1.5 \mathrm{kHz}$ and a power of $0.18 \mathrm{~W} / \mathrm{cm}^{2}$. Nitrogen is used as carrier gas, at a flow rate of $10 \mathrm{l} / \mathrm{min}$. The flow rate is controlled with an MKS mass flow controller. The precursor was injected into the plasma as an aerosol, generated with a TSI constant output atomizer at a 2 bar nitrogen pressure. With this system it is possible to create high aerosol concentrations $\left(10^{6}\right.$ particles $\left./ \mathrm{cm}^{3}\right)$ with droplet diameters around $50 \mathrm{~nm}$. Before entering the plasma the aerosol is mixed with the carrier gas. The dopant is injected with a second atomizer of the same type. In the case iodine vapor is used as dopant, the atomizer reservoir is heated up to $60^{\circ} \mathrm{C}$. The coatings where deposited onto glass substrates which were placed onto the dielectric.

\section{Analytical Techniques}

The thickness of the plasma deposited coatings was measured with an UBM profilometer.

The composition of the plasma deposited coatings was studied with an x-ray photoelectron spectrometer (XPS) from Thermo with theta probe.

The chemical structure of the plasma deposited coatings was studied with a Nexus Fourier transformed infrared spectrometer from Thermo. The samples were prepared by scraping off the coating from the glass substrate, mixing it with potassium bromide and pressing it into a pellet. The potassium bromide (99+, FTIR grade) was purchased from Sigma Aldrich and used after drying at $120^{\circ} \mathrm{C}$.

The absorption of UV and visual light by the plasma deposited coatings was measured on coatings, deposited on glass slides with a Lambda 900 UV/VIS/NIR spectrometer from Perkin Elmer.

The conductivity of the plasma deposited coatings was calculated from their resistance. Two silver electrodes were coated onto the coating surface with silver paste. The resistance of the coating was measured under a nitrogen atmosphere with a Fluke 189 True RMS multimeter. Specific conductivity was calculated from these resistance measurements.

\section{RESULTS AND DISCUSSION}

\section{Plasma Synthesis}

The polymerization of pyrrole is done in a dielectric barrier discharge (DBD) plasma reactor. The used reactor is presented in Fig. (1). Typical for this kind of reactor is its dielectric that covers at least one of the electrodes to prevent arc formation. The presence of the dielectric material makes the plasma more homogeneous. The inter electrode gap is filled with nitrogen. The nitrogen gas molecules are ionized and excited by an alternating electric field resulting in a plasma.

Injection of a monomer, such as pyrrole, into the plasma can lead to polymerization. Collision of the pyrrole molecules with the electrons and ions in the plasma activates these molecules and initiates polymerization and coating deposition. However the highly reactive plasma conditions often lead to undesired cross-linking or even degradation of the monomer structure with loss of properties. To avoid this, soft plasma conditions are necessary. By keeping the power input and frequency as low as possible, a high degree of structural retention can be obtained.

For high deposition speeds, high monomer concentrations are required. For this reason the pure monomer is sprayed into the carrier gas with an atomizer. The carrier gas transports the so formed aerosol towards the electrodes. An advantage of this approach is that a dopant can be injected simultaneously with the monomer, which leads to stable and homogeneous doping. The dopant is injected with a second atomizer which is placed just in front of the reactor. Doping of the plasma polymerized polypyrrole is done with iodine and nitrosonium tetrafluoroborate $\left(\mathrm{NOBF}_{4}\right)$. Iodine is injected as a vapor. $\mathrm{NOBF}_{4}$, is a solid that had to be dissolved in ethanol before injection.

In Table 1, the deposition rates are shown. Addition of a dopant increases the deposition rates with factor three. This is explained by the fact that polymerization of polypyrrole is an oxidative process which is enhanced by the oxidative properties of the dopants.

\section{Properties}

Conjugated polymers usually have a strong absorption in the visual range, which gives them their typical colors. The presence of this absorption is then a clear indication of an elongated conjugated system. Fig. (2) shows UV/VIS spectra of plasma polymerized polypyrrole. The polymer synthesized without dopant addition is compared with the plasma polypyrrole in situ doped with iodine or $\mathrm{NOBF}_{4}$.

Polymerization of pyrrole in a nitrogen plasma without dopant addition, results in a yellow coating. The absorption spectrum shows one peak close to the UV region, while an absorption between 400 and $500 \mathrm{~nm}$ is expected. Clearly, the conjugation length in the deposited polymer is limited. Fragmentation in the highly reactive plasma leads to many structural defects.

In situ doping with iodine vapor results in a green coating, which is the typical color for undoped polypyrrole. The absorption spectrum again shows two new absorption peaks besides the one close to the UV range. The peak at 350 


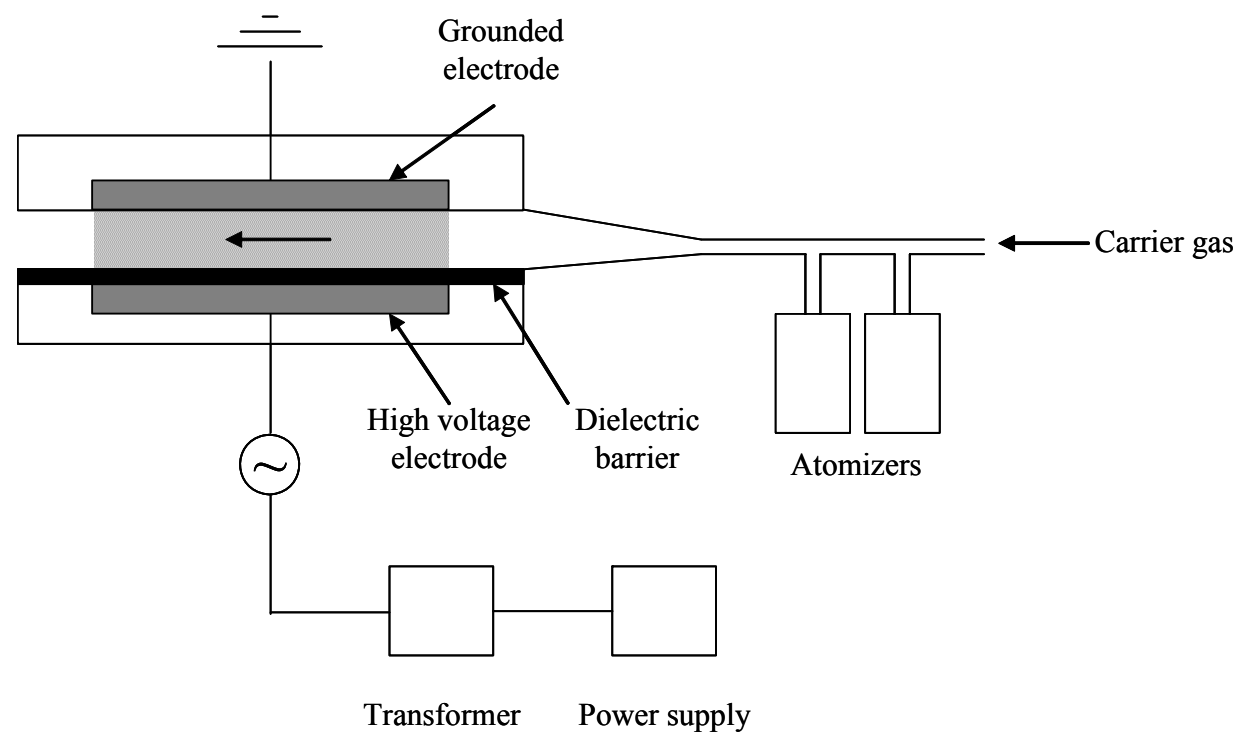

Fig. (1). Schematic presentation of a DBD plasma reactor.

$\mathrm{nm}$, probably comes from the $\mathrm{I}_{3}^{-}$anion. $\mathrm{I}_{3}^{-}$has two absorption peaks, at 290 (possible overlap with polypyrrole absorption) and $350 \mathrm{~nm}$ [26]. Another small absorption is seen at $650 \mathrm{~nm}$, which might come from a small portion of doped polypyrrole.

Addition of a $\mathrm{NOBF}_{4}$ solution during plasma polymerization of pyrrole results in a blue-black polymer, which is the expected color for doped polypyrrole. This color is explained by the UV/VIS spectrum which shows absorption in the entire visual range, with peaks around 500 and $600 \mathrm{~nm}$. The decrease in structural defects results in longer conjugation lengths. Longer conjugation results in a decrease of the energy gap between the valence and conduction band. The absorption maximum then shifts to higher wavelengths. Several absorption maxima might be seen because doping results in the formation of polarons and bipolarons, decreasing the energy gap even more [27, 28].
Table 1. Deposition Rate of Plasma Pyrrole Polymerization without Dopant Addition and In Situ Doped with Iodine or $\mathrm{NOBF}_{4}$

\begin{tabular}{|c|c|}
\hline Plasma Polypyrrole & Deposition Rate (nm/min) \\
\hline \hline Without dopant & 44 \\
\hline Iodine doped & 164 \\
\hline $\mathrm{NOBF}_{4}$ doped & 145 \\
\hline
\end{tabular}

Oxidative doping of a conjugated polymer makes it (semi)conductive, because of the extraction of electrons from the polymer chain which creates charges. Table $\mathbf{2}$ shows the conductivities of both iodine doped and $\mathrm{NOBF}_{4}$ doped plasma polymerized polypyrrole. In situ doping with $\mathrm{NOBF}_{4}$ indeed results in a conjugated polymer with conductivity in

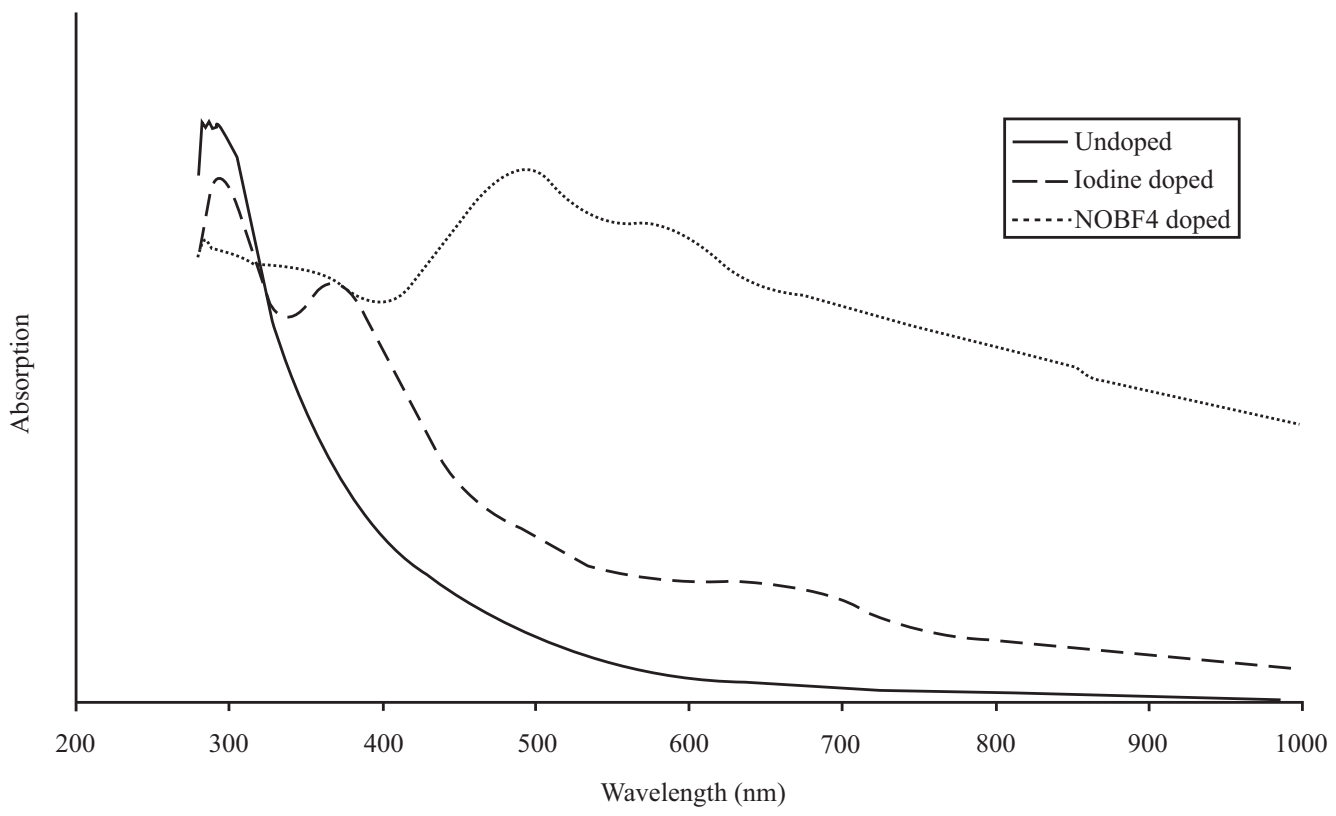

Fig. (2). UV/VIS spectra of plasma polymerized polypyrrole, without dopant addition and in situ doped with iodine or $\mathrm{NOBF}_{4}$. 
the range of the semiconductors. However, in situ iodine doped coating still acts as an insulator.

Table 2. Specific Conductivity of Plasma Polymerized Polypyrrole In Situ Doped with Iodine or $\mathrm{NOBF}_{4}$

\begin{tabular}{|c|c|}
\hline Plasma Polypyrrole & Conductivity $(\mathbf{S} / \mathbf{c m})$ \\
\hline \hline Iodine doped & $<1 \times 10^{-5}$ \\
\hline $\mathrm{NOBF}_{4}$ doped & $3,6 \times 10^{-3}$ \\
\hline
\end{tabular}

The advantage of in situ doping is that a more stable doping can be achieved when dopants with voluminous counter ions are used, which prevents leaching of the dopant. Stability of the conductivity of in situ $\mathrm{NOBF}_{4}$ doped polypyrrole under ambient conditions is shown in Fig. (3). The normalized conductivity is presented as a function of time. This normalized conductivity is the ratio of the conductivity after a certain time $\left(\sigma_{t}\right)$ and the initial conductivity $\left(\sigma_{0}\right)$ :

Normalized conductivity $=\sigma_{t} / \sigma_{0}$

After 25 days the conductivity of the $\mathrm{NOBF}_{4}$ doped plasma polypyrrole coatings has been reduced to about $20 \%$ of the initial value. This result can be compared with electrochemically synthesized and in situ doped polypyrrole/ $/ \mathrm{BF}_{4}{ }^{-}$coatings [29]. The decrease in conductivity is mainly caused by reaction of the polymer backbone with oxygen and water and also with the dopant anion [30].

\section{Polymer Structure}

From the absorption spectra in the UV and visual range, it becomes clear that the addition of a dopant/oxidant to the plasma aids in the formation of an elongated conjugated structure. While the addition of iodine leads to the formation of only a fraction of polypyrrole, the addition of $\mathrm{NOBF}_{4}$ seems to result in a doped polypyrrole coating. More insight in the absorption behavior of these two polymer depositions is gained from a structural study with FTIR and XPS spectroscopy.

Fig. (4) compares the FTIR spectra of undoped plasma polymerized polypyrrole with plasma polymerized polypyrrole in situ doped with iodine or $\mathrm{NOBF}_{4}$. Assignment of the different absorptions is presented in Table 3.

When pyrrole is polymerized at low power in a nitrogen plasma, at least part of the typical pyrrole functionalities are retained, as it can be seen in Fig. (3). Peaks around $3067 \mathrm{~cm}^{-}$ ${ }_{1}^{1}$ show that double bonds are still present. Absorption at 1406, 1449 and $1501 \mathrm{~cm}^{-1}$, result from $\mathrm{C}=\mathrm{C}$ stretches of the aromatic heterocycle. An N-H amine stretching band is present at $3442 \mathrm{~cm}^{-1}$. This peak contains a shoulder at 3268 $\mathrm{cm}^{-1}$, which is a typical value for hydrogen bonded amide functions, indicating structural degradation. Other signs of structural defects are observed in form of $\mathrm{sp}^{3}$ hybridized C-H stretches at $2936 \mathrm{~cm}^{-1}$. A peak at $2194 \mathrm{~cm}^{-1}$ shows the presence of triple bonds. Around $1700 \mathrm{~cm}^{-1}$ some carbonyl $\mathrm{C}=\mathrm{O}$ stretches are seen. The peak at $1736 \mathrm{~cm}^{-1}$ results from ketones and the one at $1633 \mathrm{~cm}^{-1}$ from amides. So, although no oxygen is added to the discharge gas, there are oxygen functionalities built into the plasma coatings. This oxygen comes from traces of oxygen in the plasma reactor or from reaction with the environmental air after plasma treatment. The appearance of all these functionalities shows that the pyrrole structure has partially degraded in the very reactive plasma. The presence of several bands around $721 \mathrm{~cm}^{-1}$ in stead of one is an indication that the substitution pattern on the aromatic ring is indeed more complex. These defects in the polymer structure shorten the conjugation length, as it was already seen in the UV/VIS spectrum.

When iodine is added to the plasma carrier gas, the same structural defects are present. At $1775 \mathrm{~cm}^{-1}$ a carbonyl stretching band is found, which was not present in plasma polypyrrole polymerized without dopant. It can be assigned to an acid iodide, which means that iodine has also bonded chemically (when used as a dopant, iodine forms $\mathrm{I}_{3}{ }^{-}$). It is

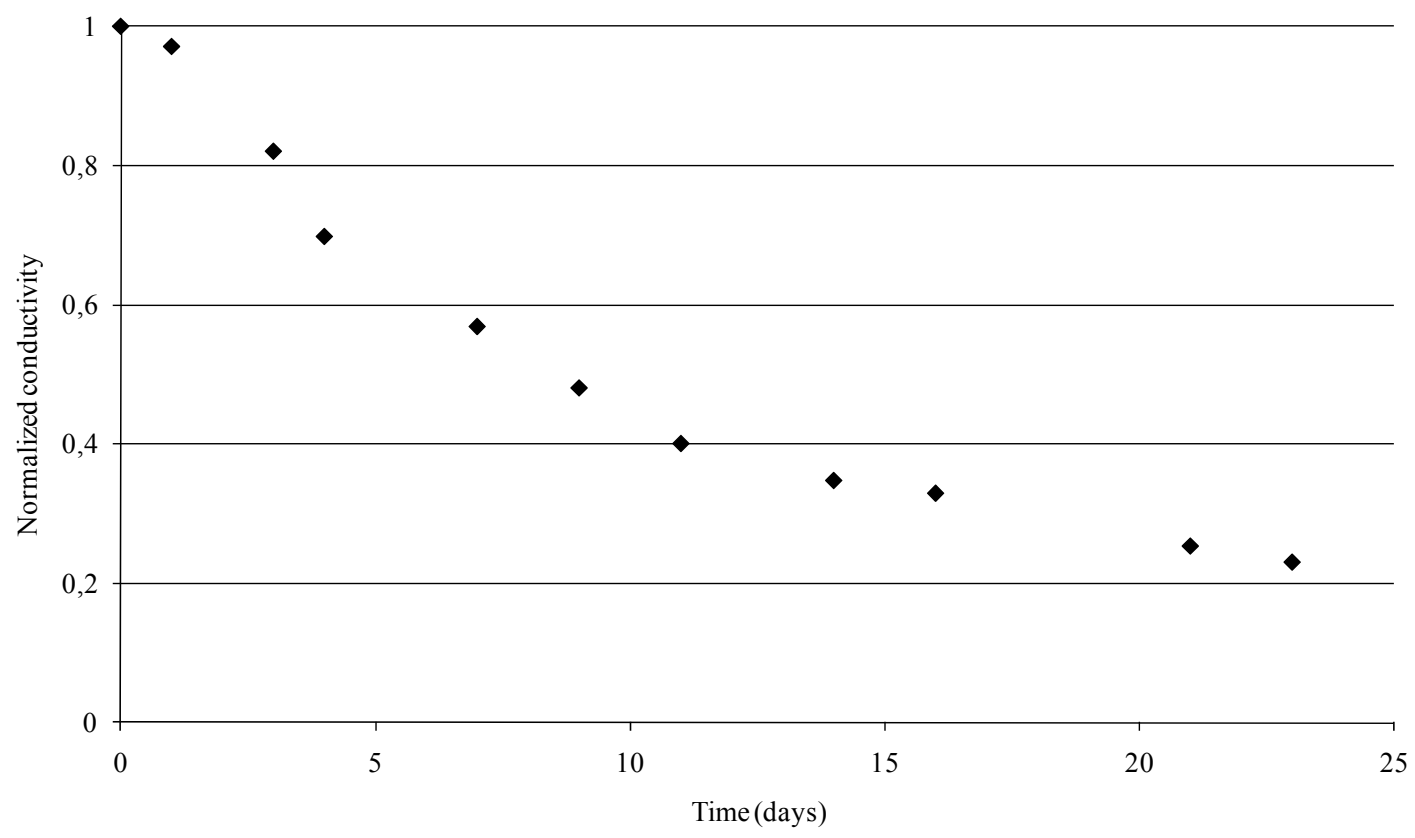

Fig. (3). Aging under ambient conditions of the conductivity of in situ $\mathrm{NOBF}_{4}$ doped plasma polymerized polypyrrole. 

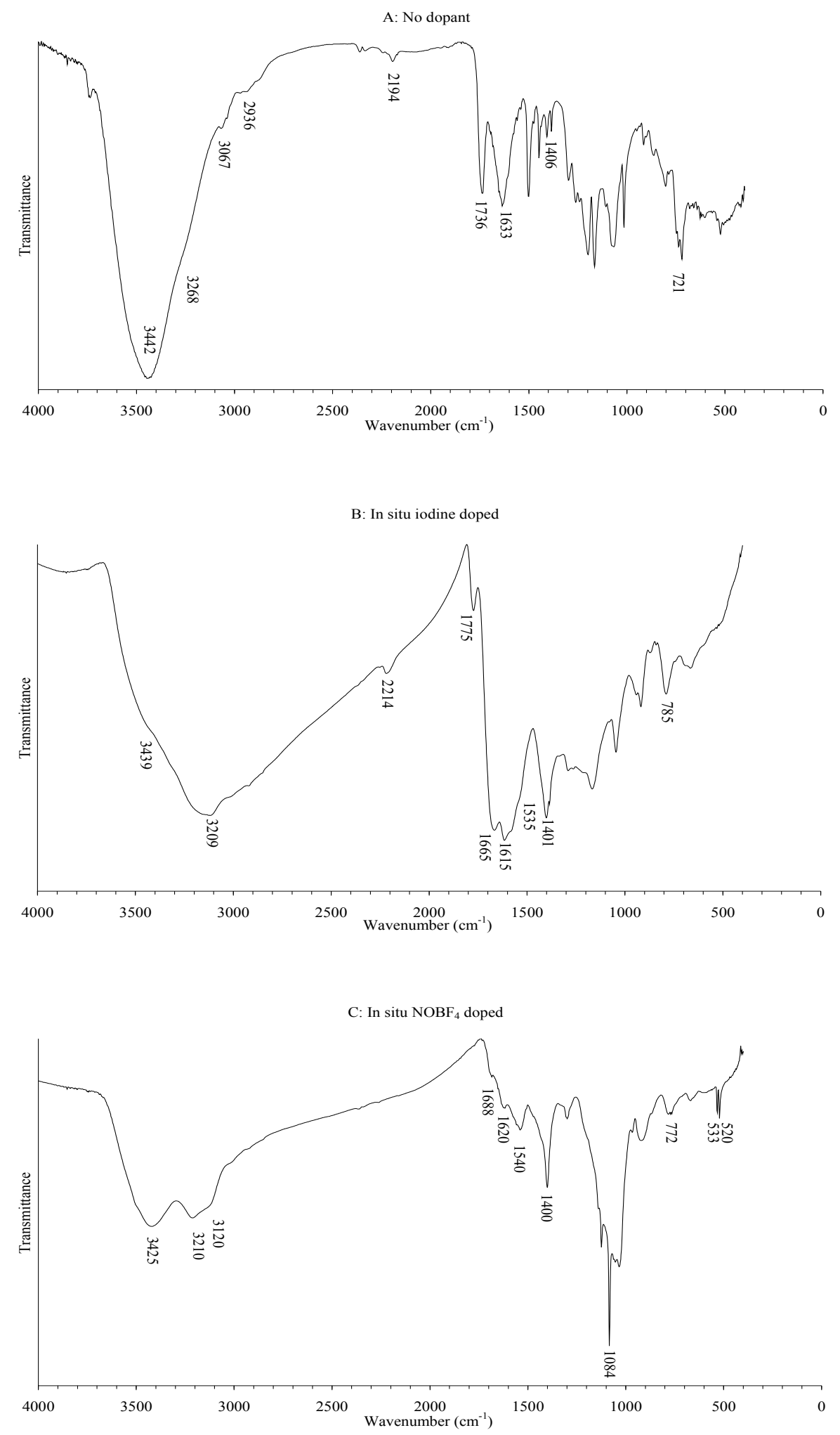

Fig. (4). Infrared spectra of plasma polymerized polypyrrole (A) and plasma polymerized polypyrrole, in situ doped with iodine (B) or $\mathrm{NOBF}_{4}(\mathbf{C})$.

clear that the addition of the oxidant iodine to the carrier gas still results in a plasma polymer with many structural defects.
The infrared spectrum of plasma polypyrrole, in situ doped with $\mathrm{NOBF}_{4}$ contains the same peaks as the iodine doped polypyrrole. However, it appears to have less defects. 
Table 3. Detailed Assignment of the FTIR Absorptions of Pyrrole and of Plasma Polymerized Polypyrrole, In Situ Doped with iodine or $\mathrm{NOBF}_{4}$

\begin{tabular}{|c|c|c|c|}
\hline Vibration & $\begin{array}{c}\text { Wabenumber }\left(\mathrm{cm}^{-1}\right) \\
\text { No Dopant }\end{array}$ & $\begin{array}{l}\text { Wavenumber }\left(\mathrm{cm}^{-1}\right) \\
\text { Iodine Doped }\end{array}$ & $\begin{array}{c}\text { Wavenumber }\left(\mathrm{cm}^{-1}\right) \\
\mathrm{NOBF}_{4} \text { Doped }\end{array}$ \\
\hline Amine N-H stretch & 3442 & 3439 & 3425 \\
\hline$=\mathrm{C}-\mathrm{H}$ stretch & $\begin{array}{l}3037 \\
3067\end{array}$ & $\begin{array}{l}3008 \\
3120\end{array}$ & $\begin{array}{l}3008 \\
3120\end{array}$ \\
\hline $\mathrm{C} \equiv \mathrm{C}$ or $\mathrm{C} \equiv \mathrm{N}$ stretch & 2194 & 2214 & - \\
\hline acid iodide $\mathrm{C}=\mathrm{O}$ stretch & - & 1775 & - \\
\hline amide $\mathrm{C}=\mathrm{O}$ stretch & 1682 & 1665 & 1688 \\
\hline amide $\mathrm{C}=\mathrm{O}$ stretch (conj.) & 1633 & 1615 & 1620 \\
\hline $\mathrm{C}-\mathrm{H}$ in plane bend & 1167 & 1164 & overlap \\
\hline C-N stretch & 1070 & 1043 & overlap \\
\hline $\mathrm{C}-\mathrm{H}$ out of plane bend & $\begin{array}{l}721 \\
736 \\
747\end{array}$ & $\begin{array}{l}915 \\
785 \\
660\end{array}$ & $\begin{array}{l}916 \\
772 \\
669\end{array}$ \\
\hline B-F bend & - & - & $\begin{array}{l}520 \\
533\end{array}$ \\
\hline
\end{tabular}

Indeed, the hydrogen bonded N-H stretch around $3200 \mathrm{~cm}^{-1}$ is less pronounced than the $\mathrm{N}-\mathrm{H}$ stretching band without hydrogen bonding around $3400 \mathrm{~cm}^{-1}$. Furthermore peaks between 1600 and $1800 \mathrm{~cm}^{-1}$, indicating oxygen functions are much smaller than in the iodine doped polypyrrole. Triple bonds are absent. These results indicate that the presence of the $\mathrm{NOBF}_{4}$ solution prevents side reactions that cause structural defects. The doublet at 520 and $533 \mathrm{~cm}^{-1}$ and the multiplet around $1084 \mathrm{~cm}^{-1}$ originate from the $\mathrm{BF}_{4}^{-}$ anion. Indeed, when $\mathrm{NOBF}_{4}$ oxidizes polypyrrole, the $\mathrm{NO}^{+}$ part of the salt is reduced, while the $\mathrm{BF}_{4}^{-}$anion stays in the coating to act as the counter ion for the positive charges created in the polymer chain. Because boron exists as two different isotopes, the B-F stretching band around $1084 \mathrm{~cm}^{-1}$ splits up in a complex multiplet [31].

More information regarding the structure of the plasma polymerized polypyrrole is achieved from XPS spectra. Table 4 presents the atomic composition as well as the molecular formula of the plasma polypyrrole. When the polymer is in situ doped with iodine, the carbon/nitrogen ratio is higher than expected. This can be explained by the elimination of nitrogen during polymerization and thus fragmentation of the aromatic ring. Another indication of structure degradation is the high oxygen content present as it was already seen in the IR spectra. The low iodine concentration in the coating is notable. The volatile iodine does not result in a stable doped polymer. Both, structure degradation and the low doping level explain the low conductivity of the plasma polymerized polypyrrole.

Table 4. Atomic Percentage and Structural Formula of Plasma Polymerized Polypyrrole, In Situ Doped with Iodine or $\mathrm{NOBF}_{4}$

\begin{tabular}{|c|c|c|c|c|c|c|c|}
\hline Dopant & C & N & O & B & F & I & Molecular Formula \\
\hline \hline Iodine & 74 & 13 & 9 & - & - & 4 & $\mathrm{C}_{4} \mathrm{~N}_{0.7} \mathrm{O}_{0.5}\left(\mathrm{I}_{2}\right)_{0.1}$ \\
\hline NOBF $_{4}$ & 30 & 12 & 5 & 12 & 41 & - & $\mathrm{C}_{4} \mathrm{~N}_{1.6} \mathrm{O}_{0.7}\left(\mathrm{BF}_{3.4}\right)_{1.6}$ \\
\hline
\end{tabular}

The situation is completely different when $\mathrm{NOBF}_{4}$ is used as dopant. Here, the nitrogen content is larger than expected. There is also a high oxygen content present in the coating, although the infrared spectra shows only little carbonyl functions. Probably the high oxygen and nitrogen content is due to unreacted and crystallized dopant encapsulated into the coating. After all, when $\mathrm{NOBF}_{4}$ is used as a dopant, $\mathrm{NO}^{+}$is the oxidizing part, while only the $\mathrm{BF}_{4}{ }^{-}$ anion stays in the coating as counter ion. The presence of some unreacted dopant in de coating can also explain the high concentration of the $\mathrm{BF}_{4}{ }^{-}$anion. The doping level that can be derived from the XPS data in table IV is thus overestimated. However if a correction is made, by assuming that all oxygen atoms belong to unreacted dopant, the molecular formula becomes $\mathrm{C}_{4} \mathrm{~N}_{0.9}\left(\mathrm{BF}_{3.4}\right)_{0.9}$. So, the doping 
level is estimated between 0.9 and 1.6 charges per monomer unit.

\section{CONCLUSIONS}

Polypyrrole coatings can be deposited with a DBD plasma reactor under atmospheric pressure. However, addition of an oxidant to the plasma is necessary to increase the deposition rate and to decrease the structural defects. Since such oxidants act as doping agents, the polypyrrole coatings get in situ doped. Co-injection of the dopant $\mathrm{NOBF}_{4}$ results in in-situ doped polypyrrole coatings with semi conductive properties in the order of $10^{-3} \mathrm{~S} / \mathrm{cm}$.

\section{CONFLICT OF INTEREST}

The authors confirm that this article content has no conflict of interest.

\section{ACKNOWLEDGEMENTS}

Declared none.

\section{REFERENCES}

[1] Shirakawa H, Louis EJ, MacDiarmid AG, Heeger AJ. Synthesis of electrically conducting organic polymers - halogen derivatives of polyacetylene, $(\mathrm{CH}) \mathrm{X}$. Chem Commun 1977; 578-80.

[2] Dodabalapur A. Organic light emitting diodes. Solid State Commun 1997; 102: 259-67.

[3] Martin RE, Geneste F, Holmes AB. Synthesis of conjugated polymers for application in light-emitting diodes (pleds). C R Acad Sci Series IV Phys 2000; 1: 447-70.

[4] Saxena V, Malhotra BD. Prospects of conducting polymers in molecular electronics. Curr Appl Phys 2003; 3: 293-305.

[5] Natali D, Sampietro M. Detectors based on organic materials: status and perspectives. Nucl Instrum Methods Phys Res A 2003; 512: 419-26.

[6] Adhikari B, Majumdar S. Polymers in sensor applications. Prog Polym Sci 2004; 29: 699-766.

[7] Nunzi JM. Organic photovoltaic materials and devices. C R Phys 2002; 3: 523-42

[8] Zarras P, Anderson N, Webber C, et al. Progress in using conductive polymers as corrosion-inhibiting coatings. Radiat Phys Chem 2003; 68: 387-94.

[9] Pron A, Rannou P. Processible conjugated polymers: from organic semiconductors to organic metals and superconductors. Prog Polym Sci 2002; 27: 135-90.

[10] Gurunathan K, Murugan AV, Marimuthu R, Mulik UP, Amalnerkar DP. Electrochemically synthesised conducting polymeric materials for applications towards technology in electronics, optoelectronics and energy storage devices. Mater Chem Phys 1999; 61: 173-91.

[11] Eufinger S, van Ooij WJ, Ridgway TH. DC plasma-polymerization of pyrrole: comparison of films formed on anode and cathode. $\mathrm{J}$ Appl Polym Sci 1996; 61: 1503-14.

[12] Zhang J, Wu MZ, Pu TS, et al. Preparation and properties of conductive lanio3 thin films by a thermal decomposition of waterbased solutions. Thin Solid Films 1997; 307: 14-20.

[13] Cruz GJ, Morales J, Olayo R. Films obtained by plasma polymerization of Pyrrole. Thin Solid Films 1999; 342: 119-26.
[14] Morales J, Olayo MG, Cruz GJ, Castillo-Ortega MM, Olayo R. Electronic conductivity of pyrrole and aniline thin films polymerized by plasma. J Polymer Sci B Polymer Phys 2000; 38: 3247-55.

[15] Shi D. Wang, SX, van Ooij WJ, et al. Uniform deposition of ultrathin polymer films on the surfaces of al2o3 nanoparticles by a plasma treatment. Appl Phys Lett 2001; 78: 1243-5.

[16] Roh JH, Lee JH, Yoon TH. Enhanced adhesion of silica for epoxy molding compounds (emcs) by plasma polymer coatings. J Adhes Sci Technol 2002; 16: 1529-43.

[17] John RK, Kumar DS. Structural, electrical and optical studies of plasma-polymerized and iodine-doped poly pyrrole. J Appl Polym Sci 2002; 83: 1856-9.

[18] Morales J, Olayo MG, Cruz GJ, Olayo R. Synthesis by plasma and characterization of bilayer aniline-pyrrole thin films doped with iodine. J Polym Sci B Polym Phys 2002; 40: 1850-6.

[19] Hosono K, Matsubara I, Murayama N, Shin W, Izu N, Kanzaki S. Structure and properties of plasma polymerized and 4ethylbenzenesulfonic acid-doped polypyrrole films. Thin Solid Films 2003; 441: 72-5.

[20] Kumar DS, Yoshida Y. Dielectric properties of plasma polymerized pyrrole thin film capacitors. Surf Coat Technol 2003; 169: 600-3.

[21] Kumar DS, Nakamura K, Nishiyama S, et al. Optical and electrical characterization of plasma polymerized pyrrole films. J Appl Phys 2003; 93: 2705-11

[22] Hosono K, Matsubara I, Murayama N, Shin W, Izu N. Effects of discharge power on the structure and electrical properties of plasma polymerized polypyrrole films. Mater Lett 2004; 58: 1371-4.

[23] Wang J, Neoh KG, Kang ET. Comparative study of chemically synthesized and plasma polymerized pyrrole and thiophene thin films. Thin Solid Films 2004; 446: 205-17.

[24] Hosono K, Matsubara I, Murayama N, Shin W, Izu N. The sensitivity of 4-ethylbenzenesulfonic acid-doped plasma polymerized polypyrrole films to volatile organic compounds. Thin Solid Films 2005; 484: 396-9.

[25] Vasquez M, Cruz GJ, Olayo MG, Timoshina T, Morales J, Olayo R. Chlorine dopants in plasma synthesized heteroaromatic polymers. Polymer 2006; 47: 7864-70.

[26] Kebede Z, Lindquist SE. Donor-acceptor interaction between nonaqueous solvents and i-2 to generate i-3(-), and its implication in dye sensitized solar cells. Solar Energy Mater Solar Cells 1999; 57: 259-75.

[27] Henry MC, Hsueh CC, Timko BP, Freund MS. Reaction of pyrrole and chlorauric acid - a new route to composite colloids. J Electrochem Soc 2001; 148: D155-62.

[28] Shigi H, Kishimoto M, Yakabe H, Deore B, Nagaoka T. Highly selective molecularly imprinted overoxidized polypyrrole colloids: one-step preparation technique. Anal Sci 2002; 18: 41-4.

[29] Brie M, Turcu R, Mihut A. Stability study of conducting polypyrrole films and polyvinylchloride-polypyrrole composites doped with different counterions. Mater Chem Phys 1997; 49: 174 8

[30] Kanyak A, Rintoul L, Graeme A. Change of mechanical and electrical properties of polypyrrole films with dopant concentration and oxidative aging. Mater Res Bull 2000; 35: 813-24.

[31] Czupinski O, Jakubas R, Pietraszko A. On structural phase transitions in 4-aminopyridinium fluoroborate [4-nh2c5h5n][bf4]: differential scanning calorimetry, dielectric and infrared studies. J Mol Struct 2004; 704: 177-87. 